\title{
PROPOSTA DE IMPLEMENTAÇÃO DO MARKETING DIGITAL NO PROCESSO DE CAPTAÇÃO DE NOVOS ALUNOS: ESTUDO DE CASO EM UMA EMPRESA DO SEGMENTO EDUCACIONAL
}

\section{ARTIGO ORIGINAL}

PINHEIRO, Jhennifer Raquel da Silva ", LIMA, ledely Kyssia Ferreira 2, COUTINHO, Andrea Chagas ${ }^{3}$, ALMEIDA, Victor da Silva ${ }^{4}$, ROBERTO, José Carlos Alves ${ }^{5}$

PINHEIRO, Jhennifer Raquel da Silva. Et al. Proposta de implementação do marketing digital no processo de captação de novos alunos: estudo de caso em uma empresa do segmento educacional. Revista Científica Multidisciplinar Núcleo do Conhecimento. Ano 06, Ed. 05, Vol. 09, pp. 05-23. Maio de 2021. ISSN: 2448-0959, Link de

acesso: https://www.nucleodoconhecimento.com.br/administracao/empresa-do-

segmento, DOI: 10.32749/nucleodoconhecimento.com.br/administracao/empresado-segmento

${ }^{1}$ Graduanda do curso de Administração.

2 Graduanda do curso de Administração.

${ }^{3}$ Graduação em Administração.

4 Coorientador. Mestre em Engenharia de Processos. Pós-Graduando em Neuropsicopedagogia Institucional. Especialista em Gestão Estratégica de RH. Graduado em Administração e Pedagogia.

${ }^{5}$ Orientador. Mestrado profissional em Engenharia de produção. Especialização em Gestão em Logística empresarial. Graduação em Administração com Ênfase em Marketing.

RC: 85127

Disponível em: https://www.nucleodoconhecimento.com.br/administracao/empresa-dosegmento 


\section{RESUMO}

O presente artigo busca analisar e implementar estratégias de marketing digital para a melhoria e funcionalidade de uma empresa do mercado educacional. Com o levantamento de dados na primeira fase do diagnóstico organizacional foi possível identificar que a área funcional do marketing da empresa $x$ estava em situação crítica por ser de pequeno porte e a falta de conhecimento da importância do marketing para captação de novos alunos. A pesquisa teve como objetivo geral analisar e aplicar as estratégias do marketing digital, e suas ferramentas na escola e como objetivos específicos, identificar nos meios bibliográficos estratégias e melhores práticas de marketing digital para o segmento educacional e esquematizar uma estratégia de introdução das ferramentas de marketing digitais na organização. A ferramenta de qualidade que foi posto em prática é $5 \mathrm{~W} 2 \mathrm{H}$, utilizando questões para a composição de planos de ações interventivas, ou seja, perguntas essenciais e respostas conforme a necessidade da empresa como: Elaborar estratégia de implementação do marketing digital no segmento educacional, propor a ferramenta benchmarking, implementar o inbound Marketing e aplicar treinamento da estratégia do marketing digital aos funcionários. Foi possível observar que as ações interventivas foram propostas mediante a ferramenta de qualidade que possibilita para instituição de ensino a promoção de melhorias no serviço e captação de novos alunos.

Palavras chave: Marketing Digital, Benchmarking, Inbound, Estratégias.

\section{INTRODUÇÃO}

O marketing é o setor mais importante de uma empresa, pois para que o negócio obtenha os resultados desejados é necessário ter controle dessa ferramenta. Com o intuito de promover, organizar, direcionar e controlar, o marketing não é responsável

RC: 85127

Disponível em: https://www.nucleodoconhecimento.com.br/administracao/empresa-dosegmento 
apenas pelas vendas de produtos ou serviços, mas também por criar um perfil da empresa e inseri-la no mercado altamente competitivo.

Isso torna o marketing um instrumento fundamental para que uma empresa obtenha as estratégias determinantes para alavancar a aquisição de novos clientes, assim como fidelizar os antigos. O marketing possui diversas tendências, ou seja, uma empresa pode utilizá-lo de formas diferentes. No momento atual, o marketing está em alta e conduzainovação e a tecnologia para outro nível de uma escala evolutiva.

O marketing digital tornou-se a maior estratégia para as organizações. Os seus recursos se dão especificamente por meio eletrônico, sendo a internet o instrumento principal para que o marketing digital ocorra, utilizando como ferramentas as redes sociais, sites e aplicativos para tratar o cliente de forma individual e personalizada, atendendo as necessidades do mesmo e construindo um relacionamento de confiança.

Esta estratégia é para buscar a fidelização do cliente, contribuindo para a maximização da receita média por cada consumidor, visando sempre a sua satisfação e lealdade à marca. Como as estratégias do marketing digital podem influenciar no crescimento da uma empresa através de diversas formas, a temática foi escolhida para ser avaliada em uma empresa do segmento educacional.

Com a avaliação realizada nas atividades de marketing digital na empresa $\mathrm{x}$, foi elaborada uma proposta de melhoria na gestão e dinâmica utilizada por essa organização. O objetivo dessa proposta de implementação é o melhor uso das plataformas digitais como ferramentas para o desenvolvimento e aplicação do marketing digital. Com o intuito de contribuir com a organização no sentido de uma maior captação de alunos e divulgação a nível nacional da empresa, pois com uma maior visibilidade se obtém vantagem e lucratividade.

RC: 85127

Disponível em: https://www.nucleodoconhecimento.com.br/administracao/empresa-do$\underline{\text { segmento }}$ 


\section{REFERENCIAL TEÓRICO}

O referencial bibliográfico refere-se à parte do desenvolvimento favorável, em que o autor expõe as afirmações de outros teóricos e pesquisas relacionadas ao tema, discutindo conforme a perspectiva do seu próprio trabalho.

Lima (2018, p. 167), afirma que o referencial bibliográfico tem como finalidadediscutir e avaliar as teorias que são mais relevantes para a pesquisa, de acordo com o tema abordado. Os principais objetivos são: definição dos conceitos-chave, avaliação e combinação de teorias e modelos relevantes, além de explicar as suposições e expectativas que orientam o projeto. Quando essas informações são apresentadas no referencial teórico há o enquadramento da pesquisa, o que justifica a abordagem, sendo baseado em ideias estabelecidas.

O referencial bibliográfico do presente artigo assenta de fontes primárias e secundárias a partir de material apurado em bases de dados digitais, como livros, publicações periódicas e artigos científicos adepto ao objetivo de melhor compreensão do tema em questão.

\subsection{CONCEITO DO MARKETING DIGITAL}

O marketing vem atuando há mais tempo do que se possa imaginar, quase tudo que é feito pode se utilizar o marketing, mesmo que em outras várias nomenclaturas adotadas. O que fez com que ocorresse uma necessidade de se aplicar as suas técnicas em todos os segmentos e áreas da economia e da sociedade, especialmente na Internet.

Segundo Leitão (2020, p. 40). "A divulgação por meios digitais é muito mais efetiva do que a tradicional pois é possível direcionar a mensagem para um público-alvo específico."

RC: 85127

Disponível em: https://www.nucleodoconhecimento.com.br/administracao/empresa-dosegmento 
Exercer marketing hoje é um desafio para empresas, organizações e profissionais que desejam projetar-se no mercado, ganhá-lo, permanecer e destacar-se nele. O marketing está plenamente relacionado à estabilidade e continuidade das organizações no mercado. Executar marketing digital é tão concreto quanto aplicar as suas técnicas tradicionais, dada a evoluçãoda internet no Brasil, no mundo e do crescimento do número de internautas.

Faustino (2019), afirma que o marketing não é uma despesa, é um investimento na empresa. Desde o design do produto e da embalagem até quantas palavras estão na página inicial de um site, tudo o que se comunica com o cliente é uma decisão de marketing e, portanto, um investimento para que o retorno ocorra, caso essa ferramenta seja aplicada de forma adequada e eficaz.

Dessa mesma forma, o meio digital e a internet são fundamentais para que as estratégias tradicionaisse expandam, pois o marketing na Internet usa várias técnicas e estratégias para direcionar o tráfego online, leads e vendas. Com esse mecanismo é possível a combinação de estratégias online para o impacto na construçãoe melhoriados relacionamentos com o público alvo e atrair mais novos clientes interessados.

Sendo assim, o marketing nas plataformas digitais é importante porque expande o alcance de uma empresa e permite que ela se conecte a mais clientes potenciais interessados em cada negócio. O marketing digital se alinha melhor com a maneira como os consumidores preferem descobrir e comprar produtos e serviços, sendo de grande importância, atualmente, para o crescimento das empresas e projetos.

\subsection{MARKETING DIGITAL NO SEGMENTO EDUCACIONAL}

O marketing digital para escolas é fundamental para garantir que a instituição seja vista nos ambientes onde seu público-alvo 'mora' de forma online. O marketing do

RC: 85127

Disponível em: https://www.nucleodoconhecimento.com.br/administracao/empresa-do$\underline{\text { segmento }}$ 
setor de educação como uma 'indústria' cresceu substancialmente nos últimos cinco anos, sendo o espaço digital a área decrescimento mais significativa.

Mendonça (2013), afirma que a facilidade de se transmitir ideias, informações, conhecimentos, entre próximos, nesta perspectiva, fez com que o especialista se apropriassem de métodos, recursos e aplicações de marketing para promover ao público alvo de forma mais eficiente.

O marketing do ramo educacional tem tudo a ver com o marketing da área local, destacando-se por meio da mídia de baixo custo em sua área local, para que você seja o mais lembrado do ponto de vista da lembrança da marca. Pois as pessoas estão em movimento, fora de casa e realizando várias tarefas, mais do que nunca. Eles não estão mais lendo jornais ou revistas como costumavam fazer.

Os instrumentos de marketing tradicionais, como outdoor, transiente, rádioe cinema, ainda podem desempenhar um papel valioso em seu mix de marketing, mas o canal dominante para publicidade direcionada em termos de uso é digital. Então, para ter sucesso no marketing de uma escola, é necessário conhecer o público alvo e saber em quais locais eles passam mais tempo, para que os planos de estratégias sejam alcançados.

Segundo Neves (2019, p 30) "O marketing digital para educação não pode ser negligenciado. É necessário planejamento para colocar em prática algumas ações. O plano de marketing visa evitar incoerências, repetições e inconsistência das ações da instituição com os usuários".

O marketing digital possui diversas estratégias, principalmente quando se trata de propaganda educacional. Mas cada uma tem propósito e grupo alvo, por isso, é muito importante potencializar um planejamento estratégico antes de investir em determinadas ações e se certificar de que serão assertivas para cada tipo de

RC: 85127

Disponível em: https://www.nucleodoconhecimento.com.br/administracao/empresa-do$\underline{\text { segmento }}$ 
negócio. Para exemplificar como funciona o marketing digital nesse setor, foi separado quatro tendências de marketing educacional, indicados para captação de novos alunos, sendo elas:

\subsubsection{CONTEÚDO EM VÍDEO}

O marketing de conteúdo de vídeo baseia-se no princípio de criar e distribuir conteúdo de vídeo valioso e consistente para seu público-alvo com o objetivo de atrair, envolver e converter leads qualificados.

Vaz (2011) "O conteúdo é todo meio de comunicação que poderá ser aplicado informações e inserindo valores ao indivíduo".

Como o marketing de conteúdo regular, o marketing de conteúdo de vídeo é uma abordagem de marketing estratégica que coloca os desejos e necessidades dos compradores em primeiro lugar para, em última instância, gerar uma ação mais lucrativa do cliente.

Conforme Leitão (2020), o conteúdo em vídeo é uma estratégia para a divulgação da instituição de ensino com o objetivo de elevar a marca entre seu grupo alvo como informar novos projetos e inovações da instituição.

O marketing de conteúdo de vídeo consiste em considerar como o vídeo pode ser integrado em cada estágio e canal de sua estratégia de marketing, juntamente com outras formas de conteúdo, como postagens em blog e podcasts. Seu foco é a criação de conteúdo de vídeo que seja útil, divertido e interessante para seu público, e que o incentive a se envolver ainda mais com o público.

RC: 85127

Disponível em: https://www.nucleodoconhecimento.com.br/administracao/empresa-dosegmento 


\subsubsection{MARKETING DE EXPERIÊNCIA}

O marketing de experiência, também conhecido como "marketing experiencial", é uma estratégia que usa eventos presenciais para promover produtos.

Conforme Parente (2016), o marketing de experiências direciona ao desenvolvimento de oportunidades criando situações para as organizações exercerem com seus clientes laços sociais por meio de ações participativa, que sejam memoráveis na percepção do cliente, gerando para a organização o capital social.

O objetivo do marketing de experiência é criar uma experiência realmente boa para o consumidor, aumentando a otimização do valor para o cliente.

Kotler (2017) afirma que quando a experiência é verdadeira coincide à viabilidade ou mesmo as atingi, desenvolvendo uma sensação de afinidade entre o cliente e a empresa, o que torna mais provável que se convertam em clientes fiéis.

A parte mais importante do marketing de experiência é criar uma experiência que valha a pena compartilhar, ou seja, algo que faça as pessoas se conectarem com uma marca e se lembrarem da ótima experiência e divulgarem de forma digital.

\subsubsection{CHATBOTS}

O marketing do chatbot é uma técnica de marketing que emprega programas de computador para automatizar as interações com clientes em potencial e clientes, seja em seu site ou em seu aplicativo, com o objetivo de gerar vendas.

SumitRaj (2019), afirma que o chatbots possui benefícios sobre os meios tradicionais de performance online, pois realiza inúmeras tarefas economizando tempo, dinheiro e atendendo as necessidades do cliente.

RC: 85127

Disponível em: https://www.nucleodoconhecimento.com.br/administracao/empresa-do$\underline{\text { segmento }}$ 
O marketing do chatbot permite que as empresas se qualifiquem e se envolvam com leads a qualquer hora e em qualquer capacidade, independentemente de sua equipe de marketing e vendas estar online ou não. Assim como é possível usar o marketing do chatbot para responder a perguntas de suporte, ele pode ser usado para iniciar conversas com os visitantes do site, qualificar leads e até mesmo fazer upsell de clientes.

\subsubsection{FIDELIZAÇÃO DE ALUNOS}

Quando um cliente/aluno é fidelizado ele é fiel a uma marca específica, eles não são facilmente influenciados pela disponibilidade ou preço. Eles estão dispostos a pagar mais contanto que obtenham o mesmo produto ou serviço de qualidade com o qual estão familiarizados e amam. Por isso, todas as empresas e escolas devem se esforçar para melhorar a lealdade do cliente para mantê-los comprando e fazer com que promovam sua marca para novos públicos.

Conforme Kotler (2006, p. 16), o "marketing de relacionamento tem como meta construir relacionamentos de longo prazo com cliente e empresa para manter um bom negócio com eles e obter bons resultados no trabalho para assim fidelizar clientes".

Independentemente do tamanho da empresa, a fidelidade do cliente é essencial. Os clientes de primeira viagem são mais difíceis de convencer porque eles não têm nenhuma experiência com os serviços ou produtos oferecidos por uma empresa. Como tal, a marca precisa de um funil de marketing abrangente para levá-los a comprar. No entanto, os clientes que já compraram em uma determinada loja estão mais acessíveis para vender porque sabem o que esperar. $\mathrm{E}$ isso funciona no ramo de marketing educacional, pois os alunos e os pais podem ser fidelizados caso o serviço oferecido pela escola seja de qualidade.

RC: 85127

Disponível em: https://www.nucleodoconhecimento.com.br/administracao/empresa-dosegmento 
Segundo Kotler (2012, p. 472)

Clientes satisfeitos são mais propensos a indicar novos clientes, o que beneficia a empresa de duas formas. Primeiro, essas referências reduzen custos de captação de novos clientes. Segundo, novo cliente ja chega com uma opniao mais elevada e certo grau de confiança previa, porque alguem que ele confia fez uma recomendação.

\subsection{A DIFERENÇA DO MARKETING TRADICIONAL E O MARKETING DIGITAL}

O marketing tradicional é o veículo de comunicação, canais convencionais onde um grupo de pessoas trabalham em uma agência onde fazem propagandas para empresas grandes ou empresas que têm dinheiro e o principal objetivo deles é com a arte e com a produção do produto para que possam chamar atenção de muita gente onde todos possam ver e falar sobre o produto.

Para Kotler (2012, p. 3) "O marketing envolve a identificação e a satisfação das necessidades humanas e sociais. Uma das mais sucintas e melhores definições de marketing é a de suprir necessidades gerando lucro".

O marketing digital é de resposta direta, onde você aposta naquela ação e espera ver resultado rápido e a partir do momento que você não obtém os resultados esperados a primeira alternativa a ser feita é tirar. Fazerdinheiro é apostar no Marketing digital.

Segundo Torres (2010), "o marketing digital tende a trazer benefícios efetivos a longo prazo. Pois faz com que o consumidor tenha um relacionamento de confiança com a empresa e fazendo com que possa ter essa troca de informações e parceria".

O Marketing digital são ações de marketing, estratégias e operacionais, adaptadas aos meios digitais e comercialização de

RC: 85127

Disponível em: https://www.nucleodoconhecimento.com.br/administracao/empresa-dosegmento 
produtos, serviços, promoções para atrair e conquistar rapidamente novos consumidores e melhorar a rede de relacionamento de maneira personalizada e com maior eficiência.(SOUSA, 2016, p. 59).

Assim sendo, a principal diferença é o foco que o Marketing tradicional tem em fazer as coisas muito bem feitas, enquanto o marketing digital tem uma grande excelência, pois realiza a divulgação e comercialização de seus produtos ou serviços por meio das mídias sociais conquistando novos usuários e melhorando a sua rede de relacionamentos.

\subsection{BENCHMARKING}

Cada vez mais as empresas estão investindo e otimizando todos os capítulos do seu dia-a-dia entre as maiores prioridades, vale a pena citar a economia e a gestão da mão-de-obra, o que gera certo destaque para o uso do "benchmarking", que consiste em arranjar maneiras de medir algo, efetuar essas medições, e tirar conclusões a partir dos resultados.

De acordo com Campos (2013), existem três tipos de benchmarking interno que é a comparação das atividades semelhantes dentro de uma mesma empresa. Competitivo compara as atividades semelhantes às dos concorrentes. Funcional que realiza a comparação das atividades semelhantes conduzidas dentro de empresas de ramos diferentes.

O trabalho do "benchmarking" nesta área se direciona a encontrar maneiras de organizar tudo aquilo que pode ser medido da melhor maneira, de modo a permitir a inteligibilidade da informação, possibilitando-nos tirar conclusões sobre o desempenho de um determinado sistema, ou de uma parte sua.

Com base nesse argumento, consideramos que "o maior e principal objetivo do benchmarking é aprender! É necessário assumir uma postura de "organização que

RC: 85127

Disponível em: https://www.nucleodoconhecimento.com.br/administracao/empresa-dosegmento 
aprende", para que possamos justificar o esforço investido no processo" (DAYCHOUM, 2018, p. 94).

Para o crescimento de uma empresa é necessário estar por dentro do andamento e segmento da concorrência, saber o que funciona e não funciona para outras organizações. O benchmarking é essencial para as empresas, porque as direcionam a aplicar melhorias nos processos comparando os procedimentos mais vantajosos e práticos de seus concorrentes.

\subsection{A IMPORTÂNCIA DO INBOUND MARKETING PARA INSTITUIÇÃO DE ENSINO}

O Inbound Marketing Educacional é uma considerável estratégia de persuasão e atração de leads. Desta forma, ao utilizar esse tipo estratégia de marketing, a instituição de ensino estará focada em captar novos e nutrir os potenciais de vendas. Por essas e outras razões, ele também é visto como Marketing de Atração ou, ainda, Marketing de permissão.

Segundo Borges (2020, p. 48) "Assim, o Inbound marketing se concentra na criação e compartilhamento de conteúdo de qualidade para mover as pessoas certas até seus canais, ou a empresa ofertante." O inbound marketing é uma pirâmide que tem como ápice atrair novos alunos, dispõe do centro para converter leads em vantagem e captação de novos alunos para instituição de ensino e por fim um fundo de fidelização ao cliente.

Conforme Rez (2016), é evidente que inbound marketing, tem como foco principal a geração de leads e a nutrição deles através de um funil de vendas, o que é extremamente aplicável no mercado B2B e também funciona em diversos mercados B2C. O mercado B2B se refere a comunicação adotada, sendo ela mais técnica e revestida para as especificações do serviço. E o funcionamento $\mathrm{B} 2 \mathrm{C}$ no segmento RC: 85127

Disponível em: https://www.nucleodoconhecimento.com.br/administracao/empresa-do$\underline{\text { segmento }}$ 
educacional apresenta a qualidade de serviços e os benefícios prestados pela instituição de ensino.

\section{MATERIAIS E MÉTODOS}

Segundo Quintilhano (2019, p. 17) a metodologia é estudo erecursos de pesquisas que podem determinar os métodos lógicos e científicos para a área de realização. A metodologia pode ser dividida por sua natureza, quais sejam de pesquisa básica ou aplicada e quanto aos meios, os mesmos dependem da sua finalidade, da metodologia empregada e do problema da pesquisa. Já os fins consistem no método que visa o objetivo final conforme o material de estudo.

Desta forma, o presente trabalho utilizou os materiais e métodos necessários para identificar e solucionar os problemas da empresa $x$, visando a melhoria da qualidade e produtividade com a implementação de estratégias do marketing digital para a captação de alunos.

\subsection{PROCEDIMENTOS METODOLÓGICOS}

Segundo Severino (2016), os procedimentos metodológicos correspondem à prioridade de métodos e formas de investigação que são utilizados no desenvolvimento da pesquisa. No presente projeto foi coletada as informações por meio de entrevistas tendo em vista a implementação de ferramentas e estratégias na presente empresa para auxiliar na produtividade.

A pesquisa teve uma abordagem mista ou quali-quantitativa, logo, o estudo é dividido em duas partes. Na primeira parte, faz-se uma análise quantitativa dos dados com uso de tabelas e gráficos e, na segunda parte, uma análise mais subjetiva, que corresponde à abordagem qualitativa de caráter exploratório e subjetivo que oentrevistador é estimulado a analisar o objeto de estudo diretamente.

RC: 85127

Disponível em: https://www.nucleodoconhecimento.com.br/administracao/empresa-do$\underline{\text { segmento }}$ 


\subsubsection{QUANTO À NATUREZA}

De acordo com Leão (2016, p. 167), a natureza da pesquisa pode ser classificada em básica e aplicada, que corresponde a forma como a pesquisa vai ser desenvolvida, de acordo com seus objetivos.

O presente trabalho utilizou dos métodoscorrespondentes à natureza aplicada, tendo em vista que o objeto de pesquisa se encontra na empresa $x$ e seus problemas específicos. Com base em estudos já realizados e coletas de dados por meio de entrevistas.

\subsubsection{QUANTO AOS FINS}

Segundo Freire (2013, p. 61), os fins da pesquisa correspondem ao procedimento de resolver os problemas, seja nos ambientes de trabalho ou nas organizações, podendo ser várias vertentes de direcionamento, os quais devem ser usados de acordo com o intuito geral da pesquisa.

Perante essa concepção, a pesquisa utilizou o método explicativo, para esclarecer e racionalizar o objeto de pesquisa com base na junção de dados coletados e resultados obtidos a partir de pesquisas em um centro educacional.

\subsubsection{QUANTO AOS MEIOS}

Segundo Lira (2019, p. 33), a pesquisa de campo se refere ao desenvolvimento de uma pesquisa longitudinal, em que se vai várias vezes ao campo, realizar a coleta das informações necessárias para se obter os resultados necessários.

O presente trabalho utilizou o método de pesquisa de campo, que corresponde a observação minuciosa dos fatos existentes por meio de coleta de dados, análise e

RC: 85127

Disponível em: https://www.nucleodoconhecimento.com.br/administracao/empresa-dosegmento 
interpretação de informações disponibilizadas pela empresa x para atingir e explicar a proposta final da pesquisa.

\subsection{CARACTERIZAÇÃO DA EMPRESA}

A empresa $x$ presta serviços na área educacional visando um desempenho e aprendizagem dos educandos. Tem como escopo as atividades de ensino préescolar em maternais e jardins-de-infância para crianças de 4 e 5 anos de idade, atividades das classes de alfabetização (CA) e ensino fundamental. Nesse período o ano letivo tem a duração de cinco anos, $1^{\circ}$ ao $5^{\circ}$ do ensino fundamental.

Possui um corpo docente treinado e capacitado para lecionar. O local conta atualmente com 23 colaboradores no seu quadro de funcionários atuando nas áreas administrativas e operacionais, entre eles jovens professores e pedagogos, serviços gerais,vigia e cozinheira.

\section{RESULTADOS E DISCUSSÕES:}

A proposta de implementação do marketing digital na instituição de ensino seria utilizar as ferramentas digitais para atrair o público alvo, pais e responsáveisatravés desse investimento de divulgação eletrônico. Sendo desenvolvido com conteúdo significativo, ou seja, a equipe que fica responsável pelo setor do marketing irá personalizar o meio de comunicação baseado nas necessidades da escola.

Com base nas pesquisas realizadas no estágio do diagnóstico organizacional, foi avaliado na empresa $x$, variáveis de desempenho da funcionalidade, pontos de suma importância em cada área funcional. O resultado está apresentado no gráfico 1.

RC: 85127

Disponível em: https://www.nucleodoconhecimento.com.br/administracao/empresa-do$\underline{\text { segmento }}$ 
Gráfico 1: Desempenho por área funcional

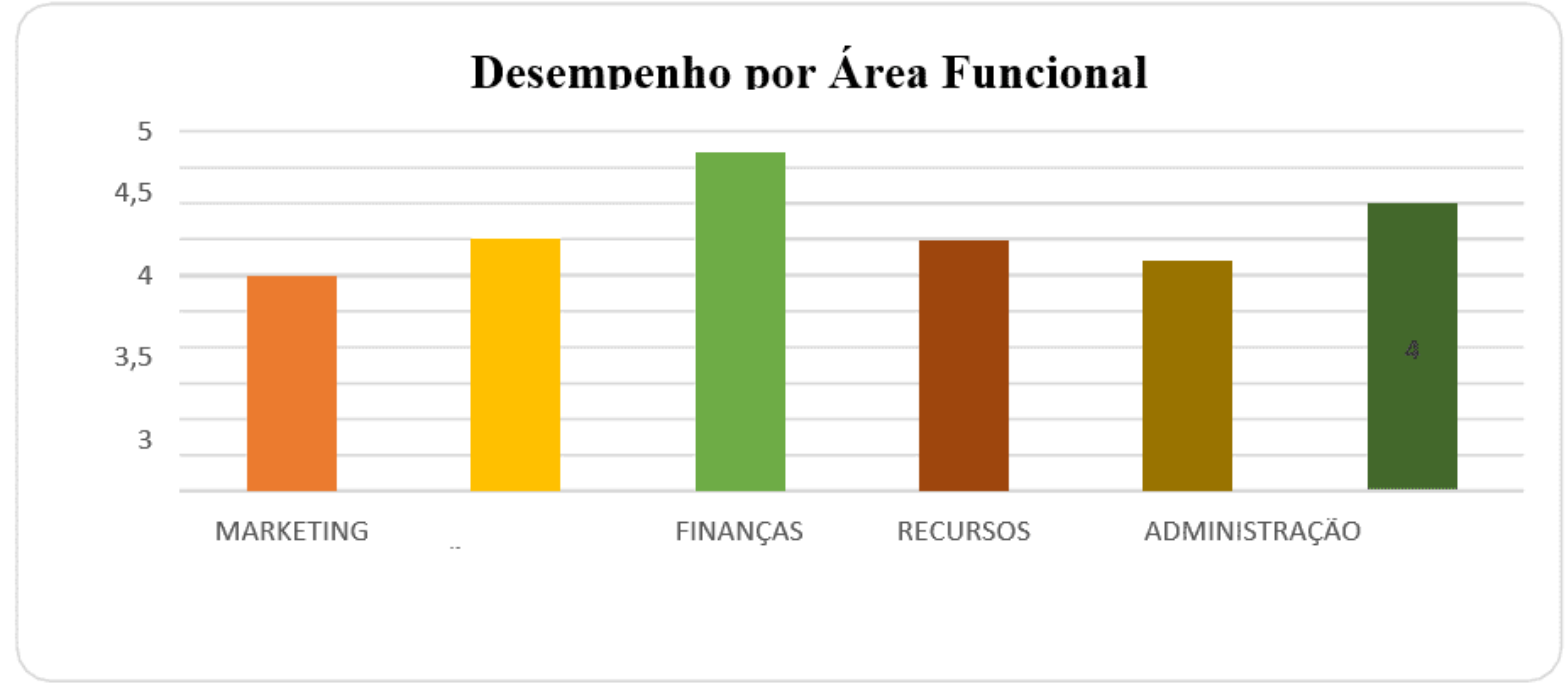

Fonte: Elaborado pelos autores fevereiro(2021)

O gráfico acima representa a média de desempenho funcional por cada área específica da instituição de ensino. Sendo assim, constatou-se que a área de finanças e logística e operacional foram as de melhor desempenho; as áreas de administração e recursos humanos foram avaliados com desempenho médio. $\mathrm{E}$ o setor com a média mais baixa foi o de marketing, sendo mostrada que essa área da empresa apresenta falhas no seu desempenho.

Quadro 01: Área funcional da empresa x

\begin{tabular}{|l|l|l|l|l|l|l|}
\hline ÁREA FUNCIONAL & \multicolumn{3}{l|l|}{ NíVEL OU GRAU DE AVALIAÇÃo } \\
\hline & $\begin{array}{l}\text { Ponto } \\
\text { muito } \\
\text { forte 5 }\end{array}$ & $\begin{array}{l}\text { Ponto } \\
\text { forte 4 }\end{array}$ & $\begin{array}{l}\text { Ponto } \\
\text { médio }\end{array}$ & $\begin{array}{l}\text { Ponto } \\
\text { fraco 2 }\end{array}$ & $\begin{array}{l}\text { Ponto } \\
\text { muito }\end{array}$ \\
\hline mARKETING & & & 3 & & \\
\hline
\end{tabular}

RC: 85127

Disponível em: https://www.nucleodoconhecimento.com.br/administracao/empresa-do$\underline{\text { segmento }}$ 


\begin{tabular}{|c|c|c|c|c|c|c|}
\hline 1 & $\begin{array}{l}\text { Qualidade dos produtos ou } \\
\text { serviço reconhecida pelo } \\
\text { mercado }\end{array}$ & & $\mathrm{x}$ & & & \\
\hline 2 & Padronização do produto & & & & $x$ & \\
\hline 3 & $\begin{array}{l}\text { Variedade de produtos } \\
\text { âncora }\end{array}$ & & & $x$ & & \\
\hline 4 & $\begin{array}{l}\text { Há empresa possui preços } \\
\text { competitivos com } 0 \\
\text { mercado }\end{array}$ & & $\mathrm{x}$ & & & \\
\hline 5 & $\begin{array}{l}\text { Há localização da empresa } \\
\text { favorece a prospecção das } \\
\text { vendas }\end{array}$ & $x$ & & & & \\
\hline 6 & $\begin{array}{l}\text { Há empresa } \\
\text { possuiestratégias de } \\
\text { comunicação visual }\end{array}$ & & & $x$ & & \\
\hline 7 & $\begin{array}{l}\text { Há empressa possuem } \\
\text { estratégias de divulgação } \\
\text { de produtos e serviços }\end{array}$ & & & & & $x$ \\
\hline 8 & $\begin{array}{l}\text { Produtos inovadores e } \\
\text { diferenciados }\end{array}$ & & & & & $x$ \\
\hline 9 & $\begin{array}{l}\text { Há empresa possuipolíticas } \\
\text { estruturadas de captação } \\
\text { de clientes }\end{array}$ & & $x$ & & & \\
\hline 10 & $\begin{array}{l}\text { Satisfação dos clientes ou } \\
\text { Cidadãos }\end{array}$ & & & $x$ & & \\
\hline \multicolumn{2}{|c|}{ TOTAL $(\Sigma)$} & 5 & 12 & 9 & 2 & 2 \\
\hline \multicolumn{2}{|c|}{$\begin{array}{l}\text { MÉDIA POR GRAU (POR } \\
\text { COLUNA) }\end{array}$} & 0,5 & 1,2 & 0,9 & 0,2 & 0,2 \\
\hline
\end{tabular}

RC: 85127

Disponível em: https://www.nucleodoconhecimento.com.br/administracao/empresa-dosegmento 


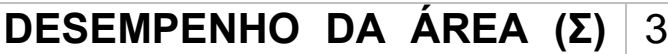 TOTAL}

Fonte: Elaborado pelos autores fevereiro(2021)

Conforme o quadro 01, observam-se itens fundamentais na área funcional do marketing na empresa $x$ do segmento educacional que estão com falta de ferramentas adequadas e padronização, sendo observado também a ausência de inovação nos serviços prestados. Considerando os dados coletados, o marketing é a área mais crítica da organização recebendo a pontuação mais baixa na avaliação de desempenho.

Com o resultado obtido, foi possível traçar estratégias para que o problema apresentando no setor de marketing possa ser solucionado. Sendo realizado um plano de ações corretivas e preventivas para tais problemas.

\subsection{PLANEJAMENTO DE AÇÕES}

De acordo com Farah et al. (2020), o planejamento de ações é uma ferramenta utilizada para organização e que segue uma metodologia definida para definir metas e objetivos, as atividades que devem ser realizadas para o alcance das etapas no prazo.

Esse planejamento foi proposto para solucionar e prevenir os problemas de desempenho apresentados pelo setor de marketing da instituição. A proposta apresentada no quadro 2 pode ser alterada e modificada na sua cronologia conforme a demanda da equipe e o conhecimento e habilidade adquiridos após as práticas contínuas.

RC: 85127

Disponível em: https://www.nucleodoconhecimento.com.br/administracao/empresa-dosegmento 
Quadro 02: Ações interventivas

\begin{tabular}{|c|c|c|c|c|}
\hline & Ações Interventivas & Cronologia & Duração & Custo \\
\hline 01 & $\begin{array}{l}\text { Elaborar estratégia de implementação do } \\
\text { marketing digital no segmento } \\
\text { educacional. }\end{array}$ & $\begin{array}{l}\text { Março } \\
\text { /2021 }\end{array}$ & 4 meses & $\begin{array}{l}R \$ \\
630,00\end{array}$ \\
\hline 02 & Propor a ferramenta benchmarking & Abril /2021 & 6 meses & $\mathrm{R} \$ 800$ \\
\hline 03 & Implementar o Inbound Marketing & Abril /2021 & 2 meses & $\begin{array}{l}R \$ \\
2.500,00\end{array}$ \\
\hline 04 & $\begin{array}{l}\text { Aplicar treinamento da estratégia do } \\
\text { marketing digital aos funcionários }\end{array}$ & Maio /2021 & 3 dias & $\begin{array}{l}\mathrm{R} \$ \\
350,00\end{array}$ \\
\hline
\end{tabular}

Fonte: Elaborado pelos autores fevereiro(2021)

A proposta de solução de cada etapa se desenvolveu por meio do uso dos métodos de $5 \mathrm{~W} 2 \mathrm{H}$. Através dessa ferramenta é possível fazer um modelo de checklist equilibrado por sete perguntas específicas e que tem as iniciais de suas palavraschave (em inglês).

Segundo Silva (2015, p. 140), a ferramenta $5 \mathrm{~W} 2 \mathrm{H}$ possui habilidades de direcionamento, baseados nas respostas formuladas de acordo com o proposto pelo método $5 \mathrm{~W} 2 \mathrm{H}$. Essa ferramenta administrativa é de fácil uso, podendo ser utilizada pelos gestores da instituição de ensino para traçar novos procedimentos estratégicos.

\subsection{IMPLEMENTAÇÃO DO INBOUND MARKETING}

A proposta de implantação do Inbound Marketing na instituição de ensino pode adquirir maior visibilidade nas mídias sociais. Tendo maior vantagem na atração de

RC: 85127

Disponível em: https://www.nucleodoconhecimento.com.br/administracao/empresa-dosegmento 
novos clientes, com a junção e aplicação da proposta nas mídias sociais, o desempenho do setor de marketing pode ser revertido a longo prazo.

Quadro 3. Proposta delmplementação do Inbound Marketing baseado nos métodos de $5 \mathrm{~W} 2 \mathrm{H}$.

\section{Implementar o Inbound Marketing}

O que? Inbound Marketing

Por quê? Alcançar o público-alvo e estabelecer comunicação com o cliente.

Onde? Empresa $X$ do segmento educacional.

Quando? Última semana de abril de 2021.

Quem? Departamento de Marketing.

Como? Por meio de planejamento e estudo em empresas como referencial.

Quanto? $\mathrm{R} \$ 2.500,00$

\subsection{APLICAÇÃO DE TREINAMENTO DA ESTRATÉGIA DO MARKETING DIGITAL AOS FUNCIONÁRIOS}

Segundo Leite e Lott (2013), o treinamento é um conjunto de ações e práticas que possuem o objetivo de capacitar os funcionários de uma organização. Essa ferramenta pode ser aplicada em qualquer setor de uma empresa, desde que seja realizada com o intuito de promover a educação profissional de uma equipe, tornando os colaboradorescada vez mais habilitados, desenvolvendo seus serviços.

A aplicação de treinamentos é essencial para uma equipe que está prestes a conhecer um novo procedimento de trabalho e, até mesmo, pode servir para aumentar as habilidades e capacitação dos profissionais. Por isso, foi um método

RC: 85127

Disponível em: https://www.nucleodoconhecimento.com.br/administracao/empresa-dosegmento 
escolhido para a proposta elaborada, já que a equipe da instituição de ensino que estuda não se prepara para usar o marketing digital.

É essencial o treinamento contínuo dessa equipe, pois ele que vai capacitar e estruturar as equipes para trabalharem com os novos mecanismos do marketing. Abaixo segue o quadro 6, que representa a proposta de estratégia de treinamentos para os funcionários do setor de marketing.

Quadro 4. Proposta de treinamento com técnica $5 \mathrm{w} 2 \mathrm{~h}$ - Treinamento da estratégia do marketing digital aos funcionários

\section{Aplicar treinamento da estratégia do marketing digital aos funcionários}

O que? Treinamento da estratégia do marketing digital aos funcionários

Por quê? Estabelecer um padrão de serviço prestado ao cliente.

Onde? Empresa $\mathrm{X}$ do segmento educacional.

Quando? Segunda semana de maio de 2021.

Quem? Departamento administrativo e departamento de marketing.

Como? Através de reuniões com os funcionários com instrutores capacitados

Quanto? R\$350,00

Fonte: Elaborado pelos autores(2021)

\section{CONSIDERAÇÕES FINAIS}

Com a pesquisa foi desenvolvido uma análise de apresentação do perfil de uma organização buscando conhecer mais sobre seu funcionamento, suas características de ramo negociale sua atuação no mercadocom o objetivo de identificar a presença de problemas e apresentar uma proposta de solução, que seja relevante e agregue valor para os serviços oferecidos pela organização.

RC: 85127

Disponível em: https://www.nucleodoconhecimento.com.br/administracao/empresa-do$\underline{\text { segmento }}$ 
Diante disso, a pesquisa teve como objetivo geral relatar as características da organização realizando uma análise críticaa fim de identificar os pontos fortes e fracos, para assim elaborar estratégias que possam trazer melhorias. Além disso, foi relatado a real situação da organização em meio a competitividade atual. $\mathrm{E} o$ resultado compreendeu que a empresa estudada apresenta uma enorme desvantagem se comparado a sua concorrência, em relação a áreas de marketing digital.

Através desse resultado foi montado um plano de ação de prevenção e intervenção nas atividades com baixo desempenho. Foi identificada a situação da empresa de modo geral tendo uma visão ampla da mesma, o que acaba evitando falhas na avaliação e no intuito de encontrar o problema.

A pesquisa partiu do desenvolvimento de buscar uma organização e realizar uma avaliação nos setores da empresa, onde seria voltado as propostas para a área que mais apresentasse erros nos processos. Como foi o caso do setor de marketing, que ainda não havia investido no segmento digital, que atualmente é considerado o método de maior visibilidade no mercado, pois a maioria das pessoas passam horas do seu dia na internet.

Sendo assim, a forma escolhida para a proposta de aplicação das ferramentas na organização das propostas para aplicação interna e externa na escola, além da possibilidade de verificar os procedimentos utilizados na empresa no setor de marketing, podendo avaliar e assim com as estratégias montadas, ser possível realizar as correções necessárias com intuito de melhoria de resultados. Portanto, a pesquisa conseguiu traçar estratégias que se aplicadas de forma adequada e contínua poderão resultar em alcance positivos no ramo de Marketing digital na organização. 
Assim, o marketing já passa a ter ênfase e a ser visto como um aliado de diferentes perfis de instituições que hoje conseguem se entender mais no comércio digital e buscam saúde financeira em suas estratégias.

\section{REFERÊNCIAS}

BORGES, A. R. Marketing digital básico: Conceitos, fundamentos e estratégias.São Paulo: Editora AgBook, 2020.

CAMPOS, V. F.Gerenciamento da rotina do trabalho do dia a dia.Minas Gerais: Editora Falconi, 2017.

DAYCHOUM, M.Ferramentas e Técnicas de gerenciamento. 7ª edição,São Paulo: Editora Brasport Livros e Multimídia Ltda, 2018.

FAUSTINO, P.Marketing digital na prática.São Paulo, SP: Editora DVS, 2019.

FARAH, O. E. et al.Empreendedorismo estratégico: criação e gestão de pequenas empresas. Cengage Learning, 2020.

FREIRE, P. F.Pedagogia da autonomia. São Paulo: Martins, 2013.

KOTLER, P.; KELLER, K. Administração de Marketing: A Bíblia do Marketing. $12^{\mathrm{a}}$ ed. São Paulo: Pearson, 2006.

KOTLER, P. et al. Administração de marketing. São Paulo: Editora Pearson Education do Brasil, 2012 - Edição 14․

KOTLER, P.K.; H.SETIWAN, I. Marketing 4.0: do tradicional ao digital. Rio de Janeiro: Sextante, 2017. 
LEÃO, L. M.Metodologia do estudo e pesquisa: facilitando a vida dos estudantes, professores e pesquisadores.Petrópolis, RJ: Editora Vozes, 2016.

LEITÃO, H. P. Marketing escolar de bolso um guia prático para o desenvolver um plano de marketing eficiente para escola da educação básica. São Paulo: Editora Arco 43, 2020.

LIMA, P. G.; PEREIRA, M. C. (orgs) Pesquisa científicas em ciências humanas e eixos procedimentais.Uberlândia: Editora Navegando Publicações, 2018.

LIRA, B. C.O passo a passo do trabalho científico. Petrópolis, RJ: Editora Vozes, 2019. Bibliografia ISBN 978-85-326-6224-8 - Edição digital.

LEITE, P. A. R.; LOTT, T. C. C. Treinamento e desenvolvimento organizacional, uma ferramenta nas empresas atuais. Revista Científica Semana Acadêmica. Fortaleza, v. 42, n. 1, 2013.

MENDONÇA, M. J. D. A. As Estratégias de Marketing de Conteúdo nas Mídias Sociais - Um Estudo de Caso da Campanha de Barack Obama Para a Presidência dos Estados Unidos em 2008. 2013.

NEVES, B. C. Marketing digital para istituições educacionais e sem fins lucrativos. Salvador, BA: Editora Copyright, 2018.

PARENTE, U. Marketing de experiência em mídias digitais, Fortaleza: Editora Expressão gráfica, 2016.

QUINTILHANO, S. R.Metodologias ativas no ensino superior práticas pedagógicas.1‥ ed. Jundiaí [SP]: Paco Editorial, 2019. 
REZ, R.Marketing de conteúdo: a moeda do século XXI. São Paulo: DVS Editora, 2016.

ROGERS, D. L.Transformação digital: repensando o seu negócio para aera digital. São Paulo: Editora Autêntica Business, 2017.

SEVERINO, J. A.Metodologia do trabalho científico. 24름. São Paulo. Ed: Cortez, 2016.

SILVA, L. C.Gestão e Melhoria de Processos: Conceito, Técnicas e Ferramentas. Tijuca/RJ: Editora Brasport Livros e Multimídia Ltda,2015.

SOUSA, N. B.Marketing tradicional ou digital. São Paulo: Editora AGBOOK, 2016.

SUMIT RAJ. Construindo Chatbots com pyton. São Paulo: Editora Novatec, 2019.

TORRES, C. A Bíblia do Marketing Digital: tudo o que você queria saber sobre o marketing e publicidade na internet e não tinha a quem perguntar. São Paulo, 2010, p. 7.

VAZ, C.A. Os 8 ps do marketing digital: 0 seu guia estratégico de marketing digital. São Paulo: Editora Novatec, 2011.

Enviado: Abril, 2021.

Aprovado: Maio, 2021. 